
7

8

\title{
Activation of rod input in a model of retinal degeneration reverses retinal remodeling and induces formation of normal synapses, circuitry and visual signaling in the adult retina
}

Zilkha Neurogenetic Institute, Department of Physiology and Neuroscience, Keck School of Medicine, University of Southern California, Los Angeles, CA 90089

Department of Ophthalmology, Stein Eye Institute, University of California, Los Angeles, CA 90095

Department of Neurobiology, Duke University School of Medicine, Durham, NC, USA

§These authors contributed equally to this work

${ }^{*}$ Correspondence should be addressed to either A.P. Sampath, G. Field or J. Chen.

Email: asampath@jsei.ucla.edu, field@neuro.duke.edu, jeannie@usc.edu

Acknowledgements: This work was supported by National Institute of Health grants EY027193 (APS, GDF, and JC); EY12155 and EY027387 (JC); an unrestricted grant from Research to Prevent Blindness to the Department of Ophthalmology, UCLA; and Jules Stein Eye Institute Core Grant EY00331 (APS). We thank Dr. M. Scalabrino for comments on the manuscript, Dr. K.Martemyanov for providing the mGluR6 antibody, Dr. C. Craft for providing the cone arrestin (ARR3) antibody and Dr. S. Ruffins at the USC microscopy core for his help with confocal imaging.

Conflict of Interest: The authors declare no competing financial interests.

Key words: Neural plasticity, neural transmission, retinal circuitry, retinal degeneration, gene therapy, cGMP-gated channel, photoreceptor cell death. 


\section{Abstract}

A major cause of human blindness is the death of rod photoreceptors. As rods degenerate, synaptic structures between rod and rod bipolar cells dissolve and the rod bipolar cells extend their dendrites and occasionally make aberrant contacts. Such changes are broadly observed in blinding disorders caused by photoreceptor cell death and is thought to occur in response to deafferentation. How the remodeled retinal circuit affect visual processing following rod rescue is not known. To address this question, we generated transgenic mice wherein a disrupted cGMP-gated channel (CNG) gene can be repaired at the endogenous locus and at different stages of degeneration by tamoxifen-inducible cre-mediated recombination. In normal rods, light-induced closure of CNG channels leads to hyperpolarization of the cell, reducing neurotransmitter release at the synapse. Similarly, rods lacking CNG channel exhibit a resting membrane potential that was $\sim 10 \mathrm{mV}$ hyperpolarized compared to WT rods, indicating diminished glutamate release. Retinas from these mice undergo stereotypic retinal remodeling as a consequence of rod malfunction and degeneration. Upon tamoxifen-induced expression of CNG channels, rods recovered their structure and exhibited normal light responses. Moreover, we show that the adult mouse retina displays a surprising degree of plasticity upon activation of rod input. Wayward bipolar cell dendrites establish contact with rods to support normal synaptic transmission, which is propagated to the retinal ganglion cells. These findings demonstrate remarkable plasticity extending beyond the developmental period and support efforts to repair or replace defective rods in patients blinded by rod degeneration.

\section{Significance Statement}

64 Current strategies for treatment of neurodegenerative disorders are focused on the repair of the primary affected cell type. However, the defective neuron functions within a complex neural circuitry, which also becomes degraded during disease. It is not known whether a rescued neuron and the remodeled circuit will establish communication to regain normal function. We show that the adult mammalian neural retina exhibits a surprising degree of plasticity following rescue of rod photoreceptors. The wayward rod bipolar cell dendrites re-establish contact with rods to support normal synaptic transmission, which is propagated to the retinal ganglion cells.

71 These findings support efforts to repair or replace defective rods in patients blinded by rod cell 72 loss. 


\section{Introduction}

Diseases that afflict sensory systems typically result from deficiencies within the sensory receptor cells themselves, either within sensory transduction or synaptic transmission

79 (Bermingham-McDonogh and Reh, 2011). Deficits in visual processing are no exception, with 80 the majority of blinding diseases resulting from the dysfunction or death of the primary input 81 cells, the retinal rod and cone photoreceptors (Quartilho et al., 2016). Synaptic remodeling of 82 retinal circuits, in particular between photoreceptor cells and their downstream neurons, occur 83 early in retinal degeneration (Soto and Kerschensteiner, 2015). Remodeling of bipolar and 84 horizontal cell dendrites is thought to occur in response to deafferentation (Marc and Jones, 85 2003). Changes that occur include homeostatic down-regulation of synaptic structures, exuberant extension of dendritic processes which sometimes contact off-target sites (Marc and Jones, 2003; Puthussery and Taylor, 2010), and even switching of post-synaptic receptor types from mGluR to iGluR expression (Chua et al., 2009). In genetically inherited forms of retinal degeneration, synaptic changes may already occur during a critical period of retinal development. It is not known how these changes in retinal circuitry may ultimately limit recovery of normal vision, although several approaches are being implemented to rescue dying photoreceptors using gene therapy, or replace them with stem cells (Scholl et al., 2016; Garg et al., 2017; Yao et al., 2018). To address this gap in knowledge, this study focuses on cellular plasticity in retinal circuits of young adult mice with rod degeneration, and how the synaptic structures and circuits that receive rod input respond to rod rescue.

We genetically engineered a mouse line in which rod function can be uniformly rescued via tamoxifen-induced cre-mediated recombination. The line was generated to lack expression of the cyclic nucleotide gated (CNG) channel beta-1 subunit (CNGB1) due to an insertion of a neomycin cassette at the endogenous gene to disrupt expression (Wang and Chen, 2014; Wang et al., 2017a). This mouse model recapitulates the effects of mutations in human CNGB1 and CNGA1 genes that cause autosomal recessive retinitis pigmentosa (Biel and Michalakis, 2007). Without the CNGB1 subunit, the CNG channels in rod outer segments fail to form normally functioning channels, which leads to a slow form of rod death that occurs over 4-6 104 months (Zhang et al., 2009; Wang et al., 2017a), or longer (Hüttl et al., 2005). Importantly, the 105 neomycin cassette is flanked by loxP sites, which allows for cre-mediated excision and the expression of CNGB1 from the endogenous locus. Thus, this mouse line provides an opportunity to introduce precisely a 'cure' for the underlying genetic defect at different time points during degeneration. 
We use this novel mouse line to determine the extent to which activating rod input in the degenerating retina allows recovery of the structure and function of well-defined rod-driven retinal circuits in young adult mice. The lack of CNG channels caused stereotypic degenerative changes in the retina that included rhodopsin mislocalization, activation of Müller glia, and a reduction of pre- and post-synaptic proteins between rods and rod bipolar cells by as early as 4

114 weeks of age. Signal transmission from rods to rod bipolar cells was abrogated and sensitivity of 115 retinal ganglion cells (RGCs) was reduced $\sim 100$-fold. Tamoxifen-induced restoration of CNG 116 channel expression initiated at 4 weeks of age led to an expected recovery of rod photoreceptor 117 function. Importantly, we show that initiation of rod input in the deafferented adult retina also 118 induced a high degree of structural plasticity between rods and their primary postsynaptic 119 partner, rod (ON) bipolar cells. Specifically, rod bipolar cell dendrites sprouted fine tips and 120 mGluR6 clusters formed on these tips which made new synapses with rods. This structural 121 transformation resulted in near-normal light responses in both bipolar cells and retinal ganglion 122 cells, the output neurons of the retina. Our findings indicate substantial plasticity in the adult 123 mammalian retina, suggesting favorable outcomes for interventions targeting the rescue of 124 dysfunctional rods from death.

\section{Materials and Methods}

127 Generation of transgenic mice. The use of mice in these experiments was in accordance with 128 the National Institutes of Health guidelines and the Institutional Animal Care and Use Committee 129 of our respective universities. Targeting of the neoloxP to the Cngb1 locus in mouse embryonic 130 stem cells and generation of transgenic mice from verified stem cell clones were described 131 previously (Chen et al., 2010). The CAGGCre-ER ${ }^{\mathrm{TM}}$ transgenic line, $\mathrm{Tg}\left(\mathrm{CAG}-\mathrm{cre} / \mathrm{Esr} 1^{*}\right) 5 \mathrm{Amc} / \mathrm{J}$, 132 was obtained from the Jackson Laboratory and crossed with Cngb $1^{\text {neo/neo }}$ mice.

Tamoxifen treatment. One-hundred mg tamoxifen was dissolved in $500 \mu \mathrm{l} 95 \%$ ethanol and diluted with $4.5 \mathrm{ml}$ corn oil to give final concentration of $20 \mathrm{mg} / \mathrm{ml}$. Four-week-old cre-positive were given a dose of $3 \mathrm{mg} / 25 \mathrm{~g}$ body weight by oral gavage for 4 or 7 consecutive days. In control experiments shown in Fig. 1, some cre-negative mice did not receive tamoxifen. For all other experiments, cre-negative littermate mice were also treated with tamoxifen to control for the possible effect of tamoxifen on photoreceptor cell survival (Wang et al., 2017b).

PCR genotyping. Genomic DNA was isolated from the neural retina. Three PCR primers were 142 used to detect the presence or absence of the neoloxP cassette. Primer 1 sequence 
143 (GTTTTATGTAGCAGAGCAGGGAC) is located on intron 19, primer 2 sequence 144 (GAGGAGTAGAAGGTGGCGC) is on neoloxP, and primer 3 sequence 145 (CCACTCCTTAGTACATACCTAAGC) is located on exon 20. Product size of 620 bp from 146 primer pairs $(2+3)$ indicates the presence of neoloxP, and a 802 bp PCR band from primer pairs $147(1+3)$ indicates the absence of the neoloxP insert.

149 Retinal morphology. Mice were rendered unconscious by isofluorane inhalation and 150 immediately followed by cervical dislocation. Retinal sections were prepared as previously 151 described (Concepcion and Chen, 2010; Wang and Chen, 2014). Briefly, before enucleation, 152 eyes were marked for orientation by cauterization on the superior aspect of the cornea. Eyes 153 were placed in $1 / 2$ Karnovsky buffer $(2.5 \%$ glutaraldehyde, $2 \%$ formaldehyde in $0.1 \mathrm{M}$ cacodylate 154 buffer, $\mathrm{pH}$ 7.2). The cornea and lens were removed, and the remaining eyecup was further fixed 155 overnight. Fixed eyes were rinsed in $0.1 \mathrm{M}$ cacodylate buffer, fixed for $1 \mathrm{~h}$ in $1 \% \mathrm{OsO}_{4}$, 156 dehydrated in graded EtOH and embedded in epoxy resin. Eyecups were hemi-sected along the 157 superior-inferior axis, and one $\mu \mathrm{m}$ sections along the central meridian were obtained for light 158 micrographs.

159 Immunocytochemistry. Eyecups were prepared as described above, except the tissues were 160 dissected in cold 4\% formaldehyde in PBS and further fixed for $15 \mathrm{~min}$ on ice. For frozen 161 sections, eyecups were rinsed in cold PBS, placed in $30 \%$ sucrose for $1 \mathrm{~h}$, embedded in Tissue162 Tek® O.C.T. Compound (Sakura® Finetek) and flash frozen in liquid $\mathrm{N}_{2}$. Ten $\mu \mathrm{m}$ frozen 163 sections were obtained. For retinal flat mounts, four relaxing cuts $\left(0^{\circ}, 90^{\circ}, 180^{\circ}, 270^{\circ}\right)$ were 164 made on the edge of the neural retina and the flattened tissue was immobilized on a piece of 165 nitrocellulose membrane (Whatman ${ }^{\circledR}$, GE Healthcare Life Sciences), photoreceptor side down, 166 as described (Anastassov et al., 2017). The tissues were incubated with the following 167 antibodies: rhodopsin 1D4 (generously provided by R. Molday), GFAP (AB5804, Millipore), 168 CtBP2 (612044, BD Biosciences), PKC (ab32376, Abcam), mGluR6 (generously provided by K. 169 Martemyanov), ARR3 (generously provided by C. Craft). Images were acquired on a Zeiss 170 LSM800 confocal microscope. For quantifications of mGluR6 puncta, images were imported into 171 Fiji (ImageJ2), adjusted to similar threshold and the number and areas of puncta were quantified 172 using the analyze particles function. 
173 Western blots. Each isolated retina was homogenized in $150 \mu$ l buffer $(150 \mathrm{mM} \mathrm{NaCl}, 50 \mathrm{mM}$

174 Tris $\mathrm{pH}$ 8.0, 0.1\% NP-40, 0.5\% deoxycholic acid, $0.1 \mathrm{mM}$ PMSF and complete mini protease

175 inhibitor (Roche Applied Sciences), incubated with DNase I (30U, Roche Applied Sciences) at

176 room temperature for $30 \mathrm{~min}$. An equal amount of retinal homogenate from each sample was

177 electrophoresed on 4-12\% Bis-Tris SDS-PAGE Gel (Invitrogen). Protein was transferred onto

178 nitrocellulose membrane (Whatman ${ }^{\circledR}$, GE Healthcare Life Sciences) and incubated overnight

179 with the following primary antibodies: rabbit anti-PDE polyclonal antibody (PAB-06800,

180 Cytosignal), rabbit anti-ROS-GC1 polyclonal antibody (sc50512, Santa Cruz), mouse Anti-G $\alpha$

181 antibody (371740, EMD4Biosciences), rabbit polyclonal anti-GCAP1 and GCAP2 antibodies

182 (Hoyo et al., 2014; Wang and Chen, 2014), mouse anti-CNGB1 4B1 antibody (Poetsch et al.,

183 2001), mouse anti-CNGa antibody PMc 1D1 (Cook et al., 1989), mouse NCKX1 8H6 antibody

184 (Vinberg et al., 2015) and mouse anti-Actin antibody (MAB1501, Millipore). The membranes

185 were then incubated with fluorescently labeled secondary antibodies (1:10,000, LI-COR

186 biosciences, 926-31081) at room temperature for 1 hour and detected by Odyssey infrared

187 imaging system.

Whole retina and single-cell recordings from rods and bipolar cells. Mice were maintained on a normal 12-hour day-night cycle and were dark-adapted overnight (>12-h) prior to experiments. All further manipulations were performed in total darkness under infrared illumination visualized with infrared image converters (BE Meyers, WA). Following euthanasia, eyes were enucleated, the lens and cornea were removed, and eyecups were stored in darkness at $32^{\circ} \mathrm{C}$ in Ames' media buffered with sodium bicarbonate (Sigma, Cat\# A1420) equilibrated with $5 \% \mathrm{CO}_{2} / 95 \% \mathrm{O}_{2}$.

Trans-retinal electroretinograms (ERGs) were recorded from isolated retinas as described previously (Pahlberg et al., 2017). Retinas were mounted photoreceptor side-up over a machined hole in a recording chamber. The tissue was superfused in darkness with $35-37^{\circ} \mathrm{C}$ Ames' media buffered with sodium bicarbonate and equilibrated with $5 \% \mathrm{CO}_{2} / 95 \% \mathrm{O}_{2}(\mathrm{pH} \sim$ 7.4). An additional $10 \mathrm{mM}$ of $\mathrm{BaCl}$ was added to the solution facing the inner retina to mitigate Müller cell activity. The trans-retinal potential change to flashes of light, delivered from a standard light bench, was measured using $\mathrm{Ag} / \mathrm{AgCl}$ half-cells connected to a differential amplifier (Model DP-311; Warner Instruments). Recordings were sampled at $1 \mathrm{kHz}$ and lowpass filtered at $30 \mathrm{~Hz}$.

Recordings of the photovoltage from individual rods and rod bipolar cells was made by whole-cell patch clamp from dark-adapted retinal slices as described previously (Pahlberg et al., 
2017). Briefly, a small piece of dark-adapted retina was embedded in low-gelling temperature agar, slices were cut on a vibrating microtome, transferred into a recording chamber, and superfused with Ames' media equilibrated with $5 \% \mathrm{CO}_{2} / 95 \% \mathrm{O}_{2}$ while maintained at $35-37^{\circ} \mathrm{C}$. The pipette internal solution consisted of (in $\mathrm{mM}$ ): $125 \mathrm{~K}$-Aspartate, $10 \mathrm{KCl}, 10 \mathrm{HEPES}, 5 \mathrm{~N}$ -

211 methyl glucamine-HEDTA, $0.5 \mathrm{CaCl}_{2}, 1 \mathrm{ATP}-\mathrm{Mg}, 0.2 \mathrm{GTP}-\mathrm{Mg}$; pH was adjusted to 7.2 with $\mathrm{N}-$

212 methyl glucamine hydroxide. Light-evoked responses were recorded following the delivery of 10

213 ms flashes from a blue LED $\left(\lambda_{\max } \sim 470 \mathrm{~nm}\right.$, full width half maximum $\left.\sim 30 \mathrm{~nm}\right)$ whose strength

214 varied from producing a just-measurable response, and increased by factors of 2 . Recordings 215 were sampled at $1 \mathrm{kHz}$ and low-pass filtered at $300 \mathrm{~Hz}$.

\section{Retinal ganglion cell recording, stimulation and analysis}

Retinal ganglion cells were recorded from dorsal retina using a large scale, dense hexagonal multi-electrode array covering $\sim 0.34 \mathrm{~mm}^{2}$ of the retina (MEA, (Field et al., 2010) 519 electrodes with $30 \mu \mathrm{m}$ spacing). The pigmented epithelium remained attached to the retina for these recordings. The retina was perfused with Ames' solution $\left(30-31^{\circ} \mathrm{C}\right)$ bubbled with $95 / 5 \%$ $\mathrm{O}_{2} / \mathrm{CO}_{2}$. Spikes were identified and assigned to specific RGCs on the MEA as previously described (Yu et al., 2017). Dim flashes were delivered at $3 \mathrm{~s}$ intervals using a $490 \mathrm{~nm}$ LED. responses were measured by counting spikes on each trial within a $100 \mathrm{~ms}$ window that was centered on the peak of the peristimulus time histogram.

\section{Experimental design and statistical analyses}

Because our initial studies did not show gender-specific differences, the genders were pooled. RGC response thresholds were measured from three Cngb1 $\triangle$ CaM retinas (102-232 cells), five Cngb $1^{\text {neo/neo }}$ retinas (100-336 cells) and three Cngb1 $1^{\text {neo/neo }}$ rescue retinas (53-186 cells). Cumulitive threshold histograms were calculated in each tissue and averaged across all retinas within a condition. A two tailed Kolmogorov-Smirnov goodness-of-fit hypothesis test was used to assess the statistical difference between average cumulative histograms. The fraction

234 of cells for which no response surpassed threshold was also measured in each recorded retina.

235 A two sample t-test was used to evaluate significance between conditions. 


\section{Results}

\section{Generation of a novel animal model of genetically reversible rod degeneration}

One challenge to identifying how plasticity among inner retinal neurons impacts functional recovery is the lack of an experimental system that is non-invasive and allows for stringent regulation of the timing and uniformity of rescue. For example, viral-mediated (gene therapy) approaches for treating rod dysfunction and death (1) take weeks for expression to occur; (2) they do not infect all targeted cells; (3) they may not drive proper protein expression levels; (4) and the subretinal injections used for viral delivery can damage the retina. A systematic investigation into the consequences of rod degeneration and subsequent rescue of the retinal circuitry requires an experimental system wherein both events occur uniformly in the retina. Towards this goal, a neoloxP cassette was inserted into intron 19 of the Cngb1 gene by homologous recombination in mouse embryonic stem cells (Fig. 1A). Mice harboring this insertion were subsequently derived $\left(C n g b 1^{\text {neo/neo }}\right)$. The presence of the cassette disrupted a splice site and prevented CNGB1 expression (Fig. 1B). Expression of CNGA1 was also substantially attenuated (Fig. 1B), a phenomenon attributed to mis-trafficking (Hüttl et al., 2005) and structural stability conferred by association of both subunits. The expression levels of other major phototransduction proteins were minimally perturbed in retinas of 1-month old (1 MO) mice (Fig. 1B, NCKX1, GC1, PDE6A, and GNAT1). Consistent with previous reports on conventional Cngb1 knockout mice (Hüttl et al., 2005; Zhang et al., 2009), the lack of CNG channel expression led to a progressive thinning of the outer nuclear layer over the course of 6 months (Fig. 1C). At two-weeks, the outer nuclear layer (ONL) containing primarily rod photoreceptor cell nuclei reached its maximum thickness. This thickness was reduced by $\sim 20 \%$ in $1 \mathrm{MO}$ mice and to $\sim 50 \%$ in $2 \mathrm{MO}$ mice. By $6 \mathrm{MO}$, the ONL was absent. Thus, these mice exhibit slow rod degeneration relative to other commonly used models of rod degenerative diseases, such as rd1 (Farber and Lolley, 1974) and rd10 mice (Chang et al., 2007).

As expected, the absence of the CNGB1 recapitulated the stereotypic sequence of events associated with rod degeneration (Marc and Jones, 2003; Puthussery and Taylor, 2010; 267 Soto and Kerschensteiner, 2015). For example, rhodopsin mislocalization and activation of

268 Müller glia were observed in 4-week old Cngb $1^{\text {neo/neo }}$ mice (Fig. 1, compare F, G with control retina, $\mathrm{D}$ and $\mathrm{E})$.

We also observed in Cngb1 $1^{\text {neo/neo }}$ mice that synaptic contacts between rods and rod

271 bipolar cells were structurally abnormal. Immunohistochemistry using a marker for the 272 presynaptic ribbon protein CtBP2 (ribeye) and the post-synaptic glutamate receptor, mGluR6, 
273 revealed clear differences between $C n g b 1^{\text {neo/neo }}$ and control retinas. In control retinas, these 274 structures were closely apposed, and both were contained within a well-defined outer plexiform 275 layer (Fig. 1H, OPL). However, in Cngb1 $1^{\text {neo/neo }}$ retinas these structures were more dispersed, 276 with synaptic ribbons retracted from rod spherules and some were situated deep into the 277 photoreceptor nuclear layer (ONL, Fig. 1I, arrows). The ultrastructure of rod synapses was 278 further evaluated by transmission electron microscopy (TEM, Fig. 1J and K). A normal rod 279 spherule (blue) contains a single large mitochondria (yellow) and encompasses a synaptic triad 280 consisting of a single ribbon (red) along with horizontal (orange) and rod bipolar cell (green) 281 processes. The majority of imaged rod spherules from control retinas exhibited this structure. 282 Dyads were also frequently observed when one or another component was out of the plane of 283 the TEM section. Of the 27 fields taken from 4 control C57 retinas, 122 synapses were counted 284 (4.5 synapses per field) wherein $64 \%$ were triads and $36 \%$ were dyads. However, in $1 \mathrm{MO}$ 285 Cngb1 $1^{\text {neo/neo }}$ retinas, the frequency of observing synapses and triadic structures were both 286 reduced (Fig. 1K). Of 31 TEM fields taken from 4 Cngb $1^{\text {neo/neo }}$ retinas, 64 synapses were 287 counted ( 2.1 synapses per field) wherein only $22 \%$ were triads and $78 \%$ of were dyads. Note, at $2881 \mathrm{MO}$, only $20 \%$ of rods had died, yet there was $>50 \%$ reduction in contacts between rods and 289 rod bipolar cells. Furthermore the contacts that persisted were largely abnormal in structure. 290 These results demonstrate that $\mathrm{Cngb} 1^{\text {neo/neo }}$ mice exhibit stereotypic slow rod degeneration and 291 that synaptic structures between rods and rod bipolar cells were disrupted.

Lack of CNGB1 expression attenuated rod photoresponses and eliminated rod bipolar cell light responses.

Previous work has indicated that lack of CNGB1 expression compromises rod vision (Biel and Michalakis, 2007). To verify compromised rod function in Cngb1 $1^{\text {neo/neo }}$ mice, we performed ex vivo whole-retina electroretinograms (ERG) under scotopic conditions. The ERG reflects the averaged activity across all retinal neurons (Granit, 1933). ERGs from C57 retinas exhibited a well characterized biphasic response (Fig 2A; see also (Saszik et al., 2002)) with the initial negative-voltage deflection (a-wave) indicative of the rod hyperpolarization to the flash stimulus, and the subsequent positive-voltage rebound indicative of predominantly the rod bipolar cell depolarization. Recordings were also performed on control Cngb1 $\triangle$ CaM mice in 303 which the calmodulin binding site was removed (Chen et al., 2010). No differences were observed between Cngb1 $\triangle$ CaM and C57 retinas (data not shown).

ERGs from $1 \mathrm{MO} C n g b 1^{\text {neo/neo }}$ retinas exhibit a diminished scotopic a-wave with reduced sensitivity (Fig. 2B), indicating minimal rod signaling without CNGB1 expression. The light 
response is not fully eliminated in these rods; this is likely due to residual activation of homomeric channels composed of CNGA1 (see Discussion). Furthermore, ERGs from $C n g b 1^{\text {neo/neo }}$ retinas did not exhibit a b-wave under scotopic conditions, indicating a lack of measurable rod-to-rod bipolar signal transmission at this gross level. This observation complements the abnormal synaptic structures observed between rods and rod bipolar cells via light and electron microscopy. Together, these results indicate that synaptic transmission between rods and rod bipolar cells is severely dysfunctional in Cngb $1^{\text {neo/neo }}$ mice. Thus, we sought to determine the extent to which normal synaptic structures and transmission between rods and rod bipolar cells could be recovered by the rescue of CNGB1 expression in mature retinas.

\section{Cre-mediated excision of the NeoLoxP cassette leads to normal CNGB1 expression.}

To activate CNGB1 expression in the the Cngb1 $1^{\text {neo/neo }}$ retina, we utilized the CAGGCre$E R^{T M}$ transgene (Hayashi and McMahon, 2002) to enable tamoxifen-dependent, cre-mediated excision of the NeoloxP cassette. We previously demonstrated that mice derived from germline excision of this cassette exhibit normal retinal morphology with a uniform and normal expression level of CNGB1 (Chen et al., 2010). The homologous recombination strategy that introduced the NeoloxP cassette also removed a stretch of 14 amino acids that encompassed the calmodulin binding domain on CNGB1 (Grunwald et al., 1998). Importantly, rods that expressed CNGB1 $\triangle$ CaM exhibited normal light responses as mentioned above (see also (Chen et al., 2010)). We hypothesize that utilizing the CAGGCre-ER ${ }^{T M}$ transgene would provide temporal control over expression of the functional CNG channel. To determine the efficacy of cremediated excision of the neoloxP cassette, four-week-old cre-positive and cre-negative Cngb $1^{\text {neo/neo }}$ littermate mice were divided into two groups. One group was given tamoxifen for four-consecutive days by oral gavage, and the other group did not receive drug treatment.

A PCR strategy was designed to detect the extent of neoloxP excision in genomic DNA extracted from isolated retinas: the primer pair $(2+3)$ detects the presence of the neoloxP insert,

334 whereas primer pair $(1+3)$ gives rise to a diagnostic band when the large neoloxP insert is excised (Fig. 3A). After four-consecutive days of tamoxifen treatment, both sets of primers produced positive bands. This result indicates a mixed population of cells at this stage, some of

337 which have undergone excision while others have not. However, when tamoxifen treatment was

338 given for seven-consecutive days a positive signal was detected only by primers $(1+3)$. This 339 result indicates that following a 7-day tamoxifen treatment, most, if not all cells have undergone 
neoloxP excision (Fig. 3A, bottom panels). Thus a 7-day treatment was used for further structural and functional studies.

To assess the level of protein expression at 6- or 8-weeks (corresponding to 1 or 3 weeks after drug treatment), Western blots were prepared from whole retinal homogenates from both cohorts (Fig. 3B). Expression of CNGB1 protein was observed only in tamoxifen-treated, cre-positive mice. No expression was observed in cre-positive mice without drug treatment, indicating a lack of basal recombinase activity. We next examined how excision of the neoloxP insert affected the expression of CNGB1 and other major phototransduction proteins. We found that following neoloxP excision, there was a striking increase in CNGB1 expression (Fig. 3C). There was also an increase in the detected levels of other phototransduction proteins GC1, PDE6A, GNAT1, and GCAP2 (Fig 3C). To determine if this is due to rod rescue, cre-negative and cre-positive Cngb1 $1^{\text {neo/neo }}$ littermate mice were administered tamoxifen for 7 consecutive days beginning at 4-weeks, and retinal sections were prepared from $3 \mathrm{MO}$ mice (Fig. 3D and $3 E)$. The ONL thickness was greater in cre-positive mice when compare to that from the crenegative sibling mice, and the rod outer segment structure was organized and of normal length. Expression of CNGB1 exhibited a long term rescuing effect on rod survival (Fig. 3F and 3G, tamoxifen was administered for 4 consecutive days starting at P28), consistent with a previous report on AAV-mediated Cngb1 gene replacement therapy (Koch et al., 2012). In sum, these data show that the $\mathrm{Cngb} 1^{\text {neo/neo }}$ mice allowed us to regulate the expression of CNGB1 from the endogenous locus in a temporally-controlled manner. Further, this excision is nearly complete with a 7-day tamoxifen treatment and that upon expression of CNGB1, the rods exhibit normal morphology and are stably rescued from cell death.

We measured the responsiveness of rod photoreceptors following drug treatment in patch-clamp recordings from individual rods in retinal slices. In voltage-clamp $\left(\mathrm{V}_{\mathrm{m}}=-40 \mathrm{mV}\right)$, rods from $1 \mathrm{MO}$ Cngb $1^{\text {neo/neo }}$ mice displayed diminished response amplitudes ( 6-fold) and a $\sim 10$-fold reduction in light sensitivity (Fig. 4A), a result consistent with the diminished a-wave in ex vivo ERG recordings (Fig. 2B). In current-clamp ( $i=0)$, Cngb1 $1^{\text {neo/neo }}$ rods exhibit a resting membrane potential that was $\sim 10 \mathrm{mV}$ hyperpolarized compared to WT rods $(-47 \pm 1.3 \mathrm{mV}$ (5) vs. $-37 \pm 2.3 \mathrm{mV}(6)$, mean $\pm \mathrm{SEM})$. These results are consistent with reduced CNG channel expression (see Discussion) and indicate reduced glutamate release in darkness. However, rods from tamoxifen treated $C n g b 1^{\text {neo/neo }}$ mice displayed responses with characteristics very

371 similar to C57 mice (Fig. 4B), consistent with near-normal function and rescue of the 372 photoreceptor layer (Fig. 3). 

cells.

Given that tamoxifen administration in $C n g b 1^{\text {neo/neo }}$ mice rescued rods from death (Fig. $3 \mathrm{E}$ ) and rescued normal rod light responses (Fig. 4), we next examined the synaptic contacts between rods and rod bipolar cells to determine how rod rescue impacts these structures. Tamoxifen treatment was initiated at 4-weeks for 7 consecutive days, and retinal structure was examined at 3M. Comparisons were made between $1 \mathrm{MO}$ C57 and Cngb1 ${ }^{\text {neo/neo }}$ mice and $3 \mathrm{MO}$ tamoxifen-treated mice to examine the effect of rod rescue that was initiated at $1 \mathrm{M}$. Synaptic structures were labeled in retinal flat mounts stained for the presynaptic ribbon synapse protein (CtBP2, blue) and postsynaptic mGluR6 (orange, Fig. 5A, 5D and 5G). To distinguish between rod and cone synapses, cone pedicles were further labeled with the cone arrestin antibody (ARR3, green). Rod bipolar cell morphology, visualized by PKC $\alpha$ staining, and the mGluR6 puncta that decorate their dendritic tips are shown in retinal cross sections (Fig. $5 \mathrm{~B}, 5 \mathrm{E}$ and $5 \mathrm{H}$ ). the mGluR6 puncta on the dendritic tips of rod bipolar cells (Fig. 5A and 5B; Fig. 1G). However, in Cngb $1^{\text {neo/neo }}$ retinas from $1 \mathrm{MO}$ mice, both the number of synaptic ribbons and mGluR6 puncta were reduced (Fig. 5D). Rod bipolar cell dendrites were also unevenly distributed in Cngb $1^{\text {neo/neo }}$ retinas, and the size of the mGluR6 puncta appeared smaller and less uniform in shape (Fig. 5E and Fig. 1H). In contrast, retinas from the tamoxifen-treated, cre-positive littermates exhibited robust staining of synaptic ribbons along with their associated mGluR6 puncta (Fig. 5G). Furthermore, rod bipolar cell dendrites were evenly extended and the mGluR6 puncta were larger in size and appeared more uniform in shape (Fig. $5 \mathrm{H}$ ). To quantify these changes, the number and size of mGluR6 puncta were measured (Fig. 5C, 5F and 5I). For the C57 retina, mGluR6 puncta size of 20- to 30-unit area were the most numerous, whereas in $\mathrm{Cngb}^{\text {neo/neo }}$ retinas smaller size puncta were more frequent (compare Fig. 5C and 5F). The distribution shifted back to larger puncta sizes in the tamoxifen-treated mice (Fig. 5I). These results indicate that inducing expression of CNGB1 in mature retina causes a recovery of synaptic structures between rods and rod bipolar cells.

\section{Rescue of CNGB1 expression in mature retina recovers rod bipolar light responses.}

The results above indicate a structural recovery of synapses following expression of CNGB1. In addition to this structural recovery, ex vivo whole-retina ERGs revealed a recovery of the rod bipolar cell-driven b-wave with amplitudes similar to control retinas (Fig. 6A). Thus, structural and functional measures broadly indicate recovery of synaptic function between rods 
and rod bipolar cells. To examine further synaptic function before and following rod rescue, we performed patch clamp recordings from rod bipolar cells in retinal slices. In untreated Cngb1 $1^{\text {neo/neo }}$ mice there was a complete absence of functional transmission of between rods and rod bipolar cells (Fig. 6C); $1 \mathrm{MO}$ Cngb1 $1^{\text {neo/neo }}$ rod bipolar cells never yielded light-evoked responses ( $n=15$ from 5 retinas), a result consistent with a lack of b-wave in ex vivo ERG recordings which represent mass-action of largely rod bipolar cells (Fig. 2B). However, in

414 Cngb $1^{\text {neo/neo }}$ mice administered tamoxifen for 7 days at 4 weeks of age and recorded at $3 \mathrm{MO}$, 415 rod bipolar cells exhibited robust light-evoked responses similar to control animals (Fig. 6D).

416 The extent of functional recovery in rod bipolar cells was characterized in plots of the response 417 amplitude versus the flash strength. These intensity-response relationships were fit with a Hill 418 curve and compared quantitatively to control responses. The half-maximal flash strength $\left(\mathrm{I}_{1 / 2}\right)$ 419 increased by $\sim 2$-fold in rescued animals (Fig. 6E), consistent with some rod loss (see 420 Discussion). However, other features of the rod bipolar light response that are critical for 421 function near visual threshold had recovered to near control values. For example, the Hill 422 exponent for the fit of the response-intensity relationship matched that in control, indicating a 423 similar nonlinear relationship between the flash strength and the response amplitude. The 424 extent of nonlinearity reflects the rate of glutamate release from rod synapses (Sampath and 425 Rieke, 2004). In addition, the time course of rod bipolar cell responses was similar in rescued 426 animals (Fig. 6A, 6C, 6E - dashed line), further indicating the anatomical and physiological 427 recovery of synaptic transmission in tamoxifen-treated animals. These results indicate that 428 rescuing rod function in the mature mouse retina produces a cascade of structural and 429 functional recovery in synaptic transmission between rods and rod bipolar cells, and thus the 430 primary rod pathway (Dacheux and Raviola, 1986).

\section{Rescuing rods recovers absolute sensitivity of retinal output}

Retinal ganglion cells (RGCs) provide the sole output from the retina and can integrate 435 (Chichilnisky and Rieke, 2005; Field and Sampath, 2017). RGC sensitivity relies on functioning 436 photoreceptors and highly tuned synaptic connections via the primary rod pathway (Field and 437 Rieke, 2002; Sampath and Rieke, 2004). To understand how rescuing rod function in the $1 \mathrm{MO}$ 438 Cngb1 $1^{\text {neo/neo }}$ retina impacts RGC sensitivity, we used a large-scale multi-electrode array (MEA) 439 to record spikes from hundreds of RGCs. We tested the sensitivity of the RGCs by stimulating 440 the retina with brief, dim flashes (0.001-10 $\mathrm{Rh} / \mathrm{rod})$ and compared $\mathrm{RGC}$ responses in $3 \mathrm{MO}$ 441 control Cngb1 $\triangle C a M, C n g b 1^{\text {neo/neo }}$, and 4-5 MO Cngb1 tamoxifen rescued mice. Flashes 
442 producing less than 1 isomerization per rod faithfully produced spike rate modulations in many

443 RGCs from control mice (Fig 7A shows an example cell). The same flash intensities did not

444 reliably modulate the spike output of most RGCs in retinas from $3 \mathrm{MO}$ old $\mathrm{Cngb} 1^{\text {neo/neo }} \mathrm{mice}$ (Fig

445 7B shows an example cell). Indeed, most RGCs from Cngb1 1neo/neo mice did not show reliable

446 responses until flash intensities exceeded $1 \mathrm{Rh}^{*} / \mathrm{rod}\left(\mathrm{Fig} 7 \mathrm{~B}_{3}\right.$ ). However, similar to the control

447 retinas, RGC responses were often evident at low flash intensities in 4-5 MO Cngb1 rescued

448 mice (Fig 7C shows an example cell). These example cells suggest that rod and circuit

449 functionality are broadly and stably rescued in some RGCs for Cngb1 rescued mice.

450 To measure the extent that sensitivity across the RGC population recovered in Cngb1 451 rescued mice, we quantified the response-threshold for all RGCs (N=1954) in MEA recordings 452 from 11 mice (3 control Cngb1 $\triangle$ CaM mice, 3 Cngb1 $1^{\text {neo/neo }}$ mice, 5 tamoxifen-treated Cngb1

453 mice). RGC response thresholds were quantified as the lowest flash intensity needed to drive 454 the average spike rate change two standard deviations above baseline (eg. Fig $7 \mathrm{~A}_{3}, 7 \mathrm{~B}_{3}, 7 \mathrm{C}_{3}$; 455 see Methods). Average RGC response threshold distributions were similar between control and 456 Cngb1 rescued mice, but were significantly higher in untreated Cngb1 ${ }^{\text {neo/neo }}$ mice (Fig 7D; KS 457 test, $p$ <0.05). Additionally, the fraction of RGCs for which no-threshold response could be 458 measured was similar between control and Cngb1 rescued mice but significantly higher in 459 untreated $\mathrm{Cngb} 1^{\text {neo/neo }}$ mice (Fig 7E; $t$-test, $\mathrm{p}<0.05$ ). These results indicate a broad and lasting 460 recovery of rod and circuit functions in Cngb1 rescued mice.

\section{Discussion}

In contrast to other neurons, rods and cones are depolarized in darkness and tonically release glutamate through ribbon synapses (Molday and Moritz, 2015), leading to saturation of rod-to-rod bipolar cell synapses (Sampath and Rieke, 2004). Light exposure causes graded hyperpolarization of the photoreceptor cell and suppression of glutamate release. Reductions in glutamate release from photoreceptors that occur during the early process of retinal degeneration lead to homeostatic changes in the downstream neurons and degrade the retinal circuit. This is seen in the dissolution of synaptic structures, dendritic sprouting, formation of ectopic contacts, and gliosis (Marc et al., 2003; Puthussery and Taylor, 2010). Although

472 strategies to rescue and restore function in defective photoreceptors have shown success for 473 regaining some visual function, gene and stem cell therapies for visual restoration are often 474 implemented in the adult; how well these rescued neurons reinstate their detailed circuitries in 475 the remodeled retina is not known. Here we examined functional restoration at the level of inner 
retinal cells and defined rod-driven circuits in the young adult mouse retina. We show that repairing a primary genetic defect in rods not only restored rod function, but also recovered normal synaptic connectivity with remodeled second order rod bipolar cells.

Rod-to-rod bipolar cell synaptic contacts are reduced in Cngb1 $^{\text {neo/neo }}$ retina and do not support synaptic transmission

The relatively slow photoreceptor degeneration we observe in the $C n g b 1^{\text {neo/neo }}$ mouse model, and observed in human patients (Bareil et al., 2001; Biel and Michalakis, 2007), may be

484 due to the fact that it is not a functional null. A small but measurable light response persisted in $485 \mathrm{Cngb}^{\text {neo/neo }}$ rods from $1 \mathrm{MO}$ mice (Fig. 4B). The residual light response is probably due to the 486 presence of homomeric channels composed of CNGA1 subunits, which are capable of 487 mediating a diminished and desensitized cGMP-dependent current (Kaupp et al., 1989). The 488 small current would reduce $\mathrm{Ca}^{2+}$ influx to the outer segment, causing increased levels of cGMP 489 through stimulation of guanylyl cyclases by $\mathrm{Ca}^{2+}$-free guanylyl cyclase activating proteins 1 and 4902 (Mendez et al., 2001; Dizhoor et al., 2010). Elevated cGMP has been shown to be a driver of 491 rod degeneration through activation of protein kinase G (Ma et al., 2015; Wang et al., 2017a). evidence for light-evoked transmission between rods and rod bipolar cells was unexpected, 494 especially given our ultrastructural evidence showing that the number of triads in the Cngb $1^{\text {neo/neo }}$ rod spherules was reduced, but not fully eliminated (Fig. 1). Therefore, it is surprising that ERGs from Cngb $1^{\text {neo/neo }}$ mice did not exhibit a scotopic b-wave, which is largely contributed by rod bipolar cells (Fig. 2B; (Saszik et al., 2002). This result was further corroborated by patch-clamp measurements from rod bipolar cells that revealed no light response, even for bright flashes delivering $\sim 2000 \mathrm{Rh} /$ rod (Fig. 6C). We speculate that this defect in synaptic transmission is due to diminished glutamate release at the ribbon synapse given that the lack of CNG channels should act as a source of "equivalent light", similar to lightinduced closure of CNG channels (see also Sampath and Rieke, 2004; Dunn et al., 2006).

503 Supporting this idea, the resting membrane potential of Cngb1 $1^{\text {neo/neo }}$ rods are $\sim 10 \mathrm{mV}$ 504 hyperpolarized due to their smaller dark current (Fig. 4A). At the rod's normal resting potential in 505 darkness $(\sim 40 \mathrm{mV})$, calcium enters through the voltage gated channel $\left(\mathrm{Ca} \mathrm{v}_{\mathrm{v}} .4\right)$ and supports 506 tonic glutamate release at the ribbon synapse (Waldner et al., 2018). Thus the hyperpolarizing 507 shift in resting potential of $C n g b 1^{\text {neo/neo }}$ rods predicts attenuated glutamate release from the rod 508 spherule. 
Interestingly, suppression of glutamate release at the rod synapse is strongly correlated with synaptic remodeling. Examples include blockade of glutamate release by tetanus toxin

511 (Cao et al., 2015), in knockout mice that lack the presynaptic Cav1.4 $\mathrm{Ca}^{2+}$ channel (Mansergh et 512 al., 2005), and in human patients diagnosed with congenital stationary night blindness (CSNB2) 513 that harbor null mutations in the gene encoding Cav1.4 (Bech-Hansen et al., 1998; Boycott et 514 al., 2000). Calcium entry through Cav1.4 channel is required for neurotransmitter release at the 515 ribbon synapse of both rods and cones. The absence of CaBP4 (Haeseleer et al., 2004) or $\alpha 2 \delta 4$ 516 (Wang et al., 2017c) that bind and regulate the activity of Cav1.4, also manifest in retinal 517 remodeling in knockout mice. These plastic changes occurred with minimal photoreceptor cell 518 loss, suggesting that synaptic remodeling is likely driven by suppression of neural transmission, 519 or deafferentation, rather than photoreceptor cell death per se. Modest synaptic changes were 520 also observed in RIBEYE knockout retinas. RIBEYE is an essential component of the synaptic 521 ribbon, and its absence abolished all presynaptic ribbons in the retina and severely impaired 522 fast and sustained neurotransmitter release (Maxeiner et al., 2016). Spontaneous miniature 523 release continues to occur without the synaptic ribbon, which may explain the milder retinal 524 remodeling phenotype observed in the RIBEYE knockout retina (Maxeiner et al., 2016).

Previous studies on two independent lines of $\mathrm{Cngb1}^{-/-}$mice have similarly reported a substantial reduction of light responses from $\mathrm{Cngb1^{-/ }}$ rods, but in both mouse lines the presence of a rod bipolar cell driven b-wave was observed (Hüttl et al., 2005; Zhang et al., 2009). The reason behind the discrepancy between those and our results is not clear, but may be due to differences in: 1) the degree of rod hyperpolarization caused by the number of functioning homomeric CNGA1 channels and hence the amount of glutamate released by rods in the different mouse lines, 2) the in vivo vs. ex vivo ERG measurements, or 3) mouse genetic

532 backgrounds.

\section{Adult rod bipolar cells demonstrate plastic changes to establish functional contacts with} rescued rods

The developmental time window for the formation of the rod to rod bipolar cell synapse 537 in mice appears to be from eye opening to postnatal day 30 (P30), during which synaptic 538 proteins are expressed, pre- and post-synaptic molecular complexes form, and the rod bipolar 539 cells develop the appropriate number of dendritic tips that make synaptic contacts with rods 540 (Anastassov et al., 2017). Some of the molecules that guide neurite growth during development 541 are absent at maturity (D'Orazi et al., 2014), and if functional connectivity of the neural retina 542 can only occur during a critical period in development, then one would expect that the adult 
543 retina may lack the ability to make such connections when rod activity is switched on after this

544 time window. Such developmental processes would have been disrupted in $\mathrm{Cngb1}{ }^{\text {neo/neo }}$ retinas,

545 wherein pronounced retinal remodeling is evident by P30 (Fig. 1). We show that tamoxifen-

546 induced CNGB1 expression between P28-P34 led to establishment of the rod's circulating

547 current in darkness and normal light responses (Fig. 4). Concomittantly, structural changes

548 were observed at the synapse: rod bipolar cells elaborated fine dendritic tips, mGluR6 receptors

549 clustered on these tips which came in close contact with presynaptic ribbons (Fig. 5G-5I). These

550 newly formed synaptic structures supported normal neural transmission, as shown by ERG

551 recordings and patch recordings from rod bipolar cells (Fig. 6), and light sensitivity in increased

552 in RGCs (Fig. 7). We hypothesize that these changes may be initiated by glutamate release at

553 the rod's synapse, similar to that which occurs at the cortex, where focal uncaging of glutamate

554 in mouse cortical layer 2/3 pyramidal neurons triggered spinogenesis from the dendrite shaft in

555 a location-specific manner (Kwon and Sabatini, 2011).

$556 \quad$ Plasticity at the photoreceptor/bipolar cell synapse has also been observed in a model of 557 photocoagulation of rabbit retina, where the laser ablation acutely removes a patch of 558 photoreceptors while leaving the inner retina intact (Beier et al., 2017). After some days, nearby 559 photoreceptors slowly migrate toward and fill in the lesioned area (Sher et al., 2013). As they do 560 so, they form functional contacts with the deafferented bipolar cells (Sher et al., 2013; Beier et 561 al., 2017). Another example of plasticity at the photoreceptor/bipolar cell synapse is the AAV562 mediated gene therapy to replace retinoschisin (RS1) in adult mice (Ou et al., 2015). Retinal 563 development of the RS1 knockout mice appears to proceed normally. However, the absence of 564 RS1, a cell adhesion protein, eventually causes splitting of the retina and a failure of synaptic 565 maintenance that manifests in reduction of the ERG b-wave amplitude (Sikkink et al., 2007). 566 This defect was reversed upon RS1 gene replacement (Ou et al., 2015). Here we demonstrate 567 for the first time that activation of rod input in young adults reversed synaptic changes that 568 occurred during development and established functional contacts with their downstream 569 neurons in the retinal circuitry of the adult retina. These results support the therapeutic potential 570 of repairing or replacing defective rods in the degenerating retina. However, a critical time 571 window for rescue likely exists: recent clinical trials for Leber Congenital Amaurosis to replace 572 RPE65 in human patients for treating a type of Leber's congenital amaurosis (LCA) caused by 573 RPE65 mutations show limited success in visual improvement, and the retina continued to 574 degenerate in some patients (Cideciyan et al., 2013). Future experimentation will address 575 whether a critical time window of rescue exists for these approaches. 


\section{References}

Anastassov IA, Wang W, Dunn FA (2017) Synaptogenesis and synaptic protein localization in the postnatal development of rod bipolar cell dendrites in mouse retina. J Comp Neurol.

Bareil C, Hamel CP, Delague V, Arnaud B, Demaille J, Claustres M (2001) Segregation of a mutation in CNGB1 encoding the beta-subunit of the rod cGMP-gated channel in a family with autosomal recessive retinitis pigmentosa. Hum Genet 108:328-334.

Bech-Hansen NT, Naylor MJ, Maybaum TA, Pearce WG, Koop B, Fishman GA, Mets M, Musarella MA, Boycott KM (1998) Loss-of-function mutations in a calcium-channel alpha1-subunit gene in Xp11.23 cause incomplete X-linked congenital stationary night blindness. Nat Genet 19:264-267.

Beier C, Hovhannisyan A, Weiser S, Kung J, Lee S, Lee DY, Huie P, Dalal R, Palanker D, Sher A (2017) Deafferented Adult Rod Bipolar Cells Create New Synapses with Photoreceptors to Restore Vision. J Neurosci 37:4635-4644.

Bermingham-McDonogh O, Reh TA (2011) Regulated reprogramming in the regeneration of sensory receptor cells. Neuron 71:389-405.

Biel M, Michalakis S (2007) Function and dysfunction of CNG channels: insights from channelopathies and mouse models. Molecular neurobiology 35:266-277.

Boycott KM, Pearce WG, Bech-Hansen NT (2000) Clinical variability among patients with incomplete $X$-linked congenital stationary night blindness and a founder mutation in CACNA1F. Can J Ophthalmol 35:204-213.

Cao Y, Sarria I, Fehlhaber KE, Kamasawa N, Orlandi C, James KN, Hazen JL, Gardner MR, Farzan M, Lee A, Baker S, Baldwin K, Sampath AP, Martemyanov KA (2015) Mechanism for Selective Synaptic Wiring of Rod Photoreceptors into the Retinal Circuitry and Its Role in Vision. Neuron 87:1248-1260.

Chang B, Hawes NL, Pardue MT, German AM, Hurd RE, Davisson MT, Nusinowitz S, Rengarajan K, Boyd AP, Sidney SS, Phillips MJ, Stewart RE, Chaudhury R, Nickerson JM, Heckenlively JR, Boatright JH (2007) Two mouse retinal degenerations caused by missense mutations in the beta-subunit of rod cGMP phosphodiesterase gene. Vision Res 47:624-633.

Chen J, Woodruff ML, Wang T, Concepcion FA, Tranchina D, Fain GL (2010) Channel modulation and the mechanism of light adaptation in mouse rods. The Journal of neuroscience : the official journal of the Society for Neuroscience 30:16232-16240.

Chichilnisky EJ, Rieke F (2005) Detection sensitivity and temporal resolution of visual signals near absolute threshold in the salamander retina. The Journal of neuroscience : the official journal of the Society for Neuroscience 25:318-330.

Chua J, Fletcher EL, Kalloniatis M (2009) Functional remodeling of glutamate receptors by inner retinal neurons occurs from an early stage of retinal degeneration. J Comp Neurol 514:473-491.

Cideciyan AV, Jacobson SG, Beltran WA, Sumaroka A, Swider M, Iwabe S, Roman AJ, Olivares MB, Schwartz SB, Komaromy AM, Hauswirth WW, Aguirre GD (2013) Human retinal gene therapy for Leber congenital amaurosis shows advancing retinal degeneration despite enduring visual improvement. Proceedings of the National Academy of Sciences of the United States of America 110:E517-525.

Concepcion F, Chen J (2010) Q344ter mutation causes mislocalization of rhodopsin molecules that are catalytically active: a mouse model of Q344ter-induced retinal degeneration. PLoS One 5:e10904.

Cook NJ, Molday LL, Reid D, Kaupp UB, Molday RS (1989) The cGMP-gated channel of bovine rod photoreceptors is localized exclusively in the plasma membrane. J Biol Chem 264:6996-6999. 
626

627

628

629

630

631

632

633

634

635

636

637

638

639

640

641

642

643

644

645

646

647

648

649

650

651

652

653

654

655

656

657

658

659

660

661

662

663

664

665

666

667

668

669

670

671

672

673

674

675

676

D'Orazi FD, Suzuki SC, Wong RO (2014) Neuronal remodeling in retinal circuit assembly, disassembly, and reassembly. Trends Neurosci 37:594-603.

Dacheux RF, Raviola E (1986) The rod pathway in the rabbit retina: a depolarizing bipolar and amacrine cell. The Journal of neuroscience : the official journal of the Society for Neuroscience 6:331-345.

Dizhoor AM, Olshevskaya EV, Peshenko IV (2010) Mg2+/Ca2+ cation binding cycle of guanylyl cyclase activating proteins (GCAPs): role in regulation of photoreceptor guanylyl cyclase. Mol Cell Biochem 334:117-124.

Farber DB, Lolley RN (1974) Cyclic guanosine monophosphate: elevation in degenerating photoreceptor cells of the C3H mouse retina. Science 186:449-451.

Field GD, Rieke F (2002) Nonlinear signal transfer from mouse rods to bipolar cells and implications for visual sensitivity. Neuron 34:773-785.

Field GD, Sampath AP (2017) Behavioural and physiological limits to vision in mammals. Philos Trans R Soc Lond B Biol Sci 372.

Field GD, Gauthier JL, Sher A, Greschner M, Machado TA, Jepson LH, Shlens J, Gunning DE, Mathieson K, Dabrowski W, Paninski L, Litke AM, Chichilnisky EJ (2010) Functional connectivity in the retina at the resolution of photoreceptors. Nature 467:673-677.

Garg A, Yang J, Lee W, Tsang SH (2017) Stem Cell Therapies in Retinal Disorders. Cells 6.

Granit R (1933) The components of the retinal action potential in mammals and their relation to the discharge in the optic nerve. J Physiol 77:207-239.

Grunwald ME, Yu WP, Yu HH, Yau KW (1998) Identification of a domain on the beta-subunit of the rod cGMP-gated cation channel that mediates inhibition by calcium-calmodulin. $J$ Biol Chem 273:9148-9157.

Haeseleer F, Imanishi Y, Maeda T, Possin DE, Maeda A, Lee A, Rieke F, Palczewski K (2004) Essential role of $\mathrm{Ca2+-binding} \mathrm{protein} \mathrm{4,} \mathrm{a} \mathrm{Cav1.4} \mathrm{channel} \mathrm{regulator,} \mathrm{in} \mathrm{photoreceptor}$ synaptic function. Nat Neurosci 7:1079-1087.

Hayashi S, McMahon AP (2002) Efficient recombination in diverse tissues by a tamoxifeninducible form of Cre: a tool for temporally regulated gene activation/inactivation in the mouse. Dev Biol 244:305-318.

Hoyo NL, Lopez-Begines S, Rosa JL, Chen J, Mendez A (2014) Functional EF-hands in neuronal calcium sensor GCAP2 determine its phosphorylation state and subcellular distribution in vivo, and are essential for photoreceptor cell integrity. PLoS Genet 10:e1004480.

Hüttl S, Michalakis S, Seeliger M, Luo DG, Acar N, Geiger H, Hudl K, Mader R, Haverkamp S, Moser M, Pfeifer A, Gerstner A, Yau KW, Biel M (2005) Impaired channel targeting and retinal degeneration in mice lacking the cyclic nucleotide-gated channel subunit CNGB1. J Neurosci 25:130-138.

Kaupp UB, Niidome T, Tanabe T, Terada S, Bonigk W, Stuhmer W, Cook NJ, Kangawa K, Matsuo $\mathrm{H}$, Hirose $\mathrm{T}$, et al. (1989) Primary structure and functional expression from complementary DNA of the rod photoreceptor cyclic GMP-gated channel. Nature 342:762-766.

Koch S, Sothilingam V, Garcia Garrido M, Tanimoto N, Becirovic E, Koch F, Seide C, Beck SC, Seeliger MW, Biel M, Muhlfriedel R, Michalakis S (2012) Gene therapy restores vision and delays degeneration in the CNGB1(-/-) mouse model of retinitis pigmentosa. Hum Mol Genet 21:4486-4496.

Kwon HB, Sabatini BL (2011) Glutamate induces de novo growth of functional spines in developing cortex. Nature 474:100-104.

Ma H, Butler MR, Thapa A, Belcher J, Yang F, Baehr W, Biel M, Michalakis S, Ding XQ (2015) cGMP/Protein Kinase G Signaling Suppresses Inositol 1,4,5-Trisphosphate Receptor Phosphorylation and Promotes Endoplasmic Reticulum Stress in Photoreceptors of Cyclic Nucleotide-gated Channel-deficient Mice. J Biol Chem 290:20880-20892. 
677

678

679

680

681

682

683

684

685

686

687

688

689

690

691

692

693

694

695

696

697

698

699

700

701

702

703

704

705

706

707

708

709

710

711

712

713

714

715

716

717

718

719

720

721

722

723

724

725

726

727

Mansergh F, Orton NC, Vessey JP, Lalonde MR, Stell WK, Tremblay F, Barnes S, Rancourt DE, Bech-Hansen NT (2005) Mutation of the calcium channel gene Cacna1f disrupts calcium signaling, synaptic transmission and cellular organization in mouse retina. Hum Mol Genet 14:3035-3046.

Marc RE, Jones BW (2003) Retinal remodeling in inherited photoreceptor degenerations. Mol Neurobiol 28:139-147.

Marc RE, Jones BW, Watt CB, Strettoi E (2003) Neural remodeling in retinal degeneration. Prog Retin Eye Res 22:607-655.

Maxeiner S, Luo F, Tan A, Schmitz F, Sudhof TC (2016) How to make a synaptic ribbon: RIBEYE deletion abolishes ribbons in retinal synapses and disrupts neurotransmitter release. Embo J 35:1098-1114.

Mendez A, Burns ME, Sokal I, Dizhoor AM, Baehr W, Palczewski K, Baylor DA, Chen J (2001) Role of guanylate cyclase-activating proteins (GCAPs) in setting the flash sensitivity of rod photoreceptors. Proc Natl Acad Sci U S A 98:9948-9953.

Molday RS, Moritz OL (2015) Photoreceptors at a glance. J Cell Sci 128:4039-4045.

Ou J, Vijayasarathy C, Ziccardi L, Chen S, Zeng Y, Marangoni D, Pope JG, Bush RA, Wu Z, Li W, Sieving PA (2015) Synaptic pathology and therapeutic repair in adult retinoschisis mouse by AAV-RS1 transfer. J Clin Invest 125:2891-2903.

Pahlberg J, Frederiksen R, Pollock GE, Miyagishima KJ, Sampath AP, Cornwall MC (2017) Voltage-sensitive conductances increase the sensitivity of rod photoresponses following pigment bleaching. J Physiol 595:3459-3469.

Poetsch A, Molday LL, Molday RS (2001) The cGMP-gated channel and related glutamic acidrich proteins interact with peripherin-2 at the rim region of rod photoreceptor disc membranes. J Biol Chem 276:48009-48016.

Puthussery T, Taylor WR (2010) Functional changes in inner retinal neurons in animal models of photoreceptor degeneration. Adv Exp Med Biol 664:525-532.

Quartilho A, Simkiss P, Zekite A, Xing W, Wormald R, Bunce C (2016) Leading causes of certifiable visual loss in England and Wales during the year ending 31 March 2013. Eye (Lond) 30:602-607.

Sampath AP, Rieke F (2004) Selective transmission of single photon responses by saturation at the rod-to-rod bipolar synapse. Neuron 41:431-443.

Saszik SM, Robson JG, Frishman LJ (2002) The scotopic threshold response of the darkadapted electroretinogram of the mouse. J Physiol 543:899-916.

Scholl HP, Strauss RW, Singh MS, Dalkara D, Roska B, Picaud S, Sahel JA (2016) Emerging therapies for inherited retinal degeneration. Sci Transl Med 8:368rv366.

Sher A, Jones BW, Huie P, Paulus YM, Lavinsky D, Leung LS, Nomoto H, Beier C, Marc RE, Palanker D (2013) Restoration of retinal structure and function after selective photocoagulation. J Neurosci 33:6800-6808.

Sikkink SK, Biswas S, Parry NR, Stanga PE, Trump D (2007) X-linked retinoschisis: an update. J Med Genet 44:225-232.

Soto F, Kerschensteiner D (2015) Synaptic remodeling of neuronal circuits in early retinal degeneration. Front Cell Neurosci 9:395.

Vinberg F, Wang T, Molday RS, Chen J, Kefalov VJ (2015) A new mouse model for stationary night blindness with mutant SIc24a1 explains the pathophysiology of the associated human disease. Human molecular genetics 24:5915-5929.

Waldner DM, Bech-Hansen NT, Stell WK (2018) Channeling Vision: CaV1.4-A Critical Link in Retinal Signal Transmission. Biomed Res Int 2018:7272630.

Wang T, Chen J (2014) Induction of the unfolded protein response by constitutive G-protein signaling in rod photoreceptor cells. J Biol Chem 289:29310-29321.

Wang T, Tsang SH, Chen J (2017a) Two pathways of rod photoreceptor cell death induced by elevated cGMP. Hum Mol Genet 26:2299-2306. 

Wong WT (2017b) Tamoxifen Provides Structural and Functional Rescue in Murine Models of Photoreceptor Degeneration. J Neurosci 37:3294-3310.

Wang Y, Fehlhaber KE, Sarria I, Cao Y, Ingram NT, Guerrero-Given D, Throesch B, Baldwin K, Kamasawa N, Ohtsuka T, Sampath AP, Martemyanov KA (2017c) The Auxiliary Calcium Channel Subunit alpha2delta4 is Required for Axonal Elaboration, Synaptic Transmission, and Wiring of Rod Photoreceptors. Neuron 93:1359-1374 e1356.

Yao K, Qiu S, Wang YV, Park SJH, Mohns EJ, Mehta B, Liu X, Chang B, Zenisek D, Crair MC, Demb JB, Chen B (2018) Restoration of vision after de novo genesis of rod photoreceptors in mammalian retinas. Nature 560:484-488.

Yu WQ, Grzywacz NM, Lee EJ, Field GD (2017) Cell type-specific changes in retinal ganglion cell function induced by rod death and cone reorganization in rats. J Neurophysiol 118:434-454.

Zhang Y, Molday LL, Molday RS, Sarfare SS, Woodruff ML, Fain GL, Kraft TW, Pittler SJ (2009) Knockout of GARPs and the beta-subunit of the rod cGMP-gated channel disrupts disk morphogenesis and rod outer segment structural integrity. J Cell Sci 122:1192-1200. 


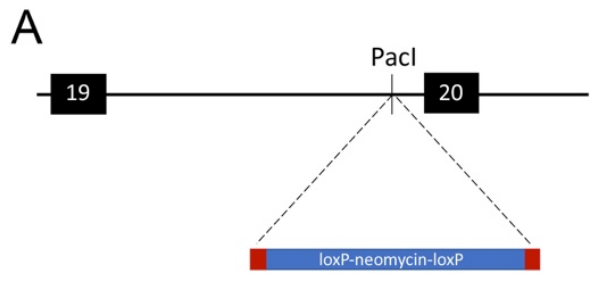

C

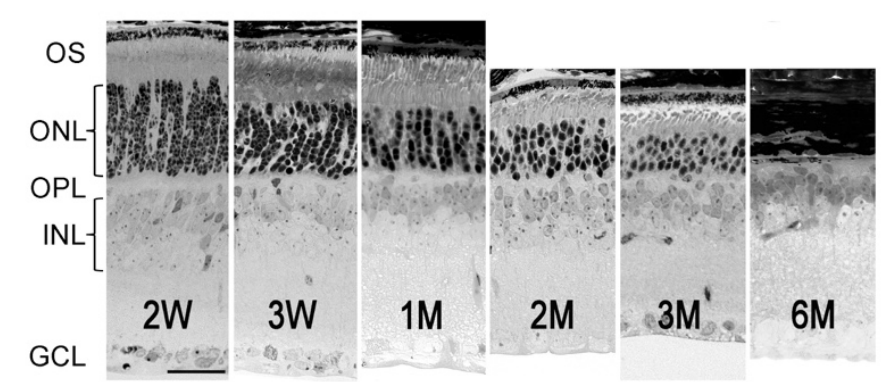

B
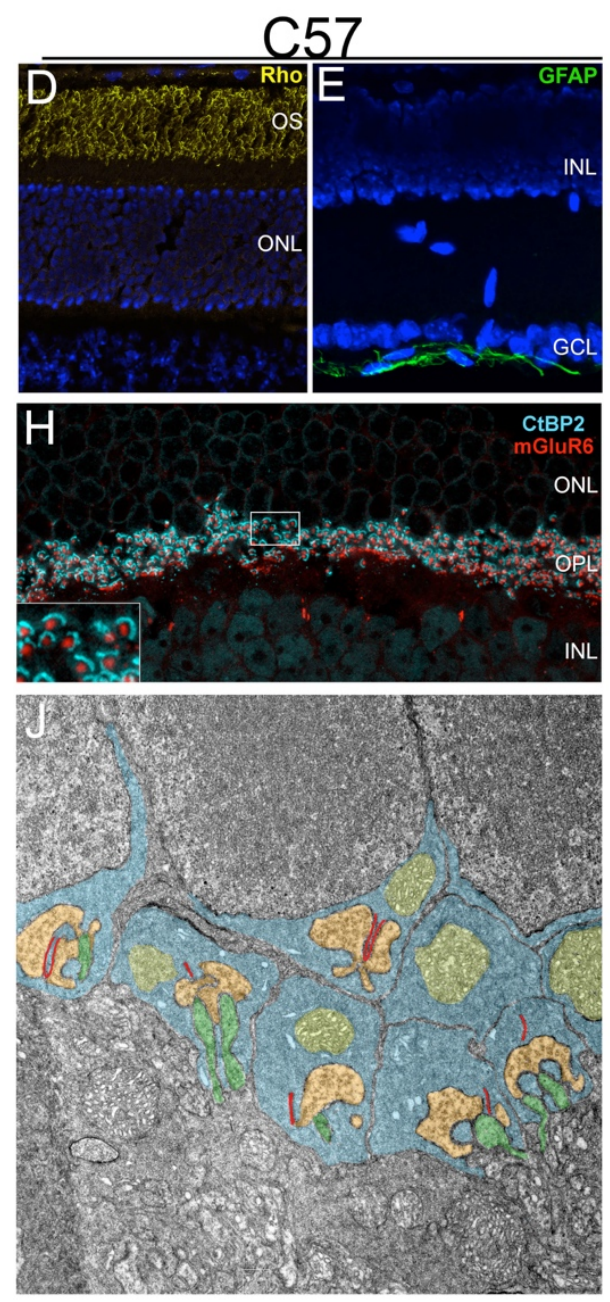
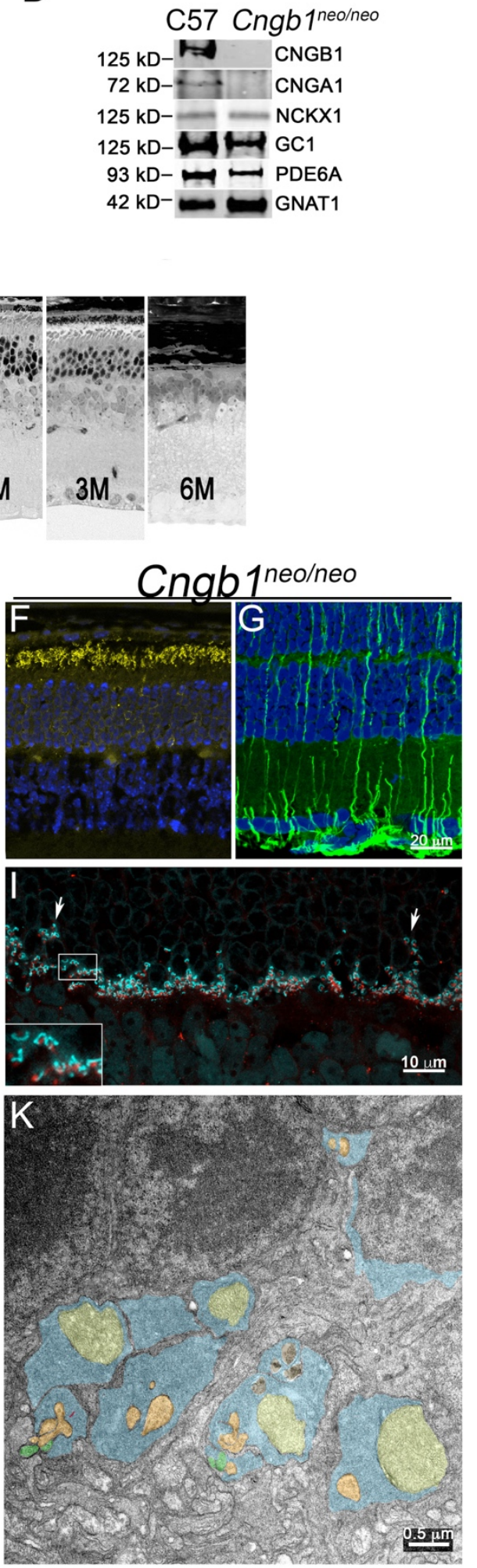
Figure 1. Retinas from $C n g b 1^{\text {neo/neo }}$ mice exhibit stereotypic degenerative changes. $(A)$ The 1.8 $\mathrm{kb}$ neomycin cassette, flanked by loxP sites, was inserted into intron 19 of the Cngb1 gene. (B). Western blots of retinal homogenates from control and Cngb $1^{\text {neo/neo }}$ mice show that the neomycin insertion blocked expression of CNGB1, and down regulated expression of CNGA1 channel proteins. C. Light micrograph of representative retinal sections prepared from Cngb1 $1^{\text {neo/neo }}$ mice at the indicated ages. Scale bar $=20 \mu \mathrm{m}$. (D-I) Cryosections from $1 \mathrm{MO}$ C57 (left panels) and $1 \mathrm{MO}$ Cngb $1^{\text {neo/neo }}$ mice (right panels). Rhodopsin is localized to the outer segment (D) and GFAP to the inner limiting membrane proximal to the ganglion cell layer (E) in C57 retina. In contrast, the outer segment of mutant retina is shortened, and rhodopsin is mislocalized to the outer nuclear layer $(F)$, and GFAP immunoreactivity extends to the entire retina (G). Nuclei are stained with DAPI (blue). (H) C57 and (I) Cngb1 ${ }^{\text {neo/neo }}$ retinal sections stained for synaptic ribbons (CtBP2, blue) of photoreceptors and mGluR6 puncta (red) of bipolar cell dendrites. Transmission electron microscopy of C57 (J) and Cngb $1^{\text {neo/neo }}(\mathrm{K})$ retinal sections. Color coding is as follows: rod spherule (blue), mitochondria (yellow), synaptic ribbon (red), horizontal cell (orange) and rod bipolar cell (green). OS, outer segment; ONL, outer nuclear layer; OPL, outer plexiform layer; INL, inner nuclear layer; GCL, ganglion cell layer. 

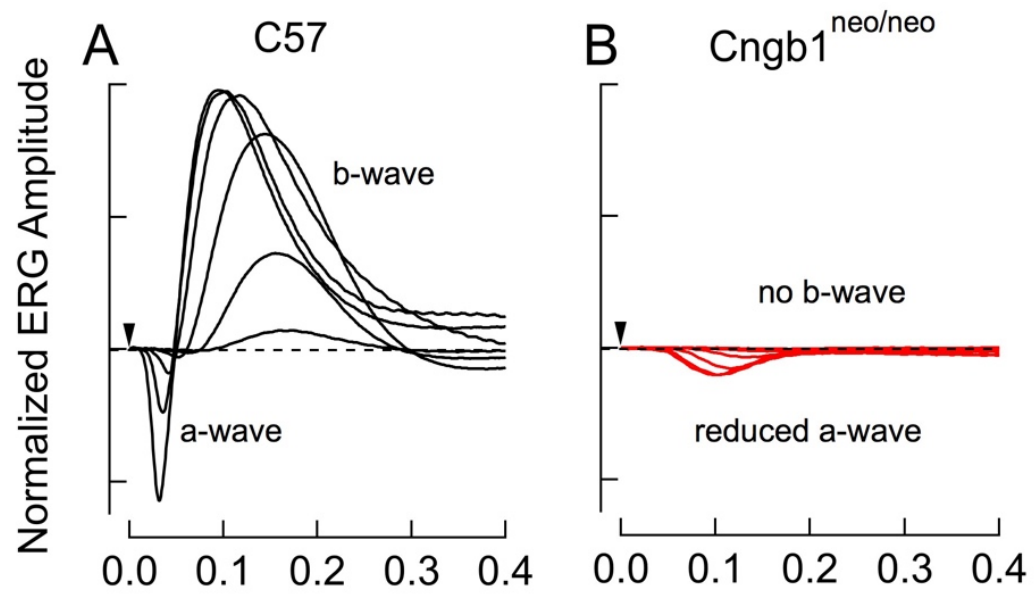

Time (s)

Figure 2. Characterization of rod function by ex-vivo electroretinography (ERGs). (A) ERG recordings from a $3 \mathrm{MO}$ C57 mouse show normal a- and b-waves (rod and RBC responses, respectively). Flashes generated 2, 9, 35, 140, 560, and $2200 \mathrm{Rh} / \mathrm{rod}(\mathrm{B}) \mathrm{ERG}$ from $1 \mathrm{MO}$ $C n g b 1^{\text {neo/neo }}$ mice show total absence of the b-wave, consistent with disrupted rod-to-RBC signaling. Flashes generated 550, 2200, 8800, 18,000, and 35,000 Rh*/rod. 
A
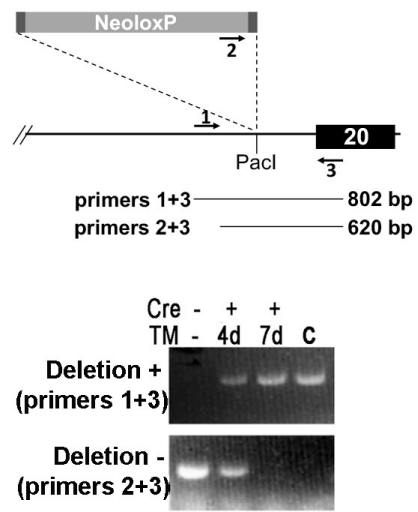

B
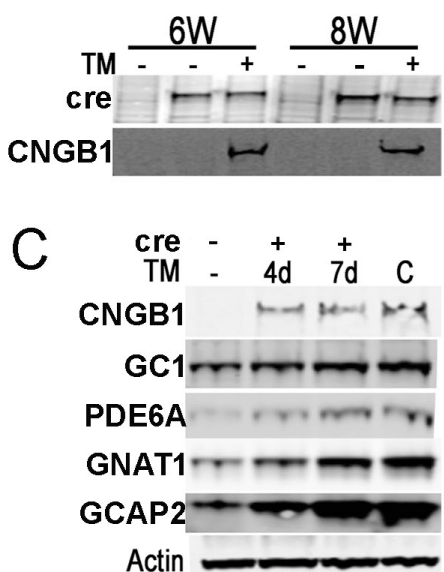
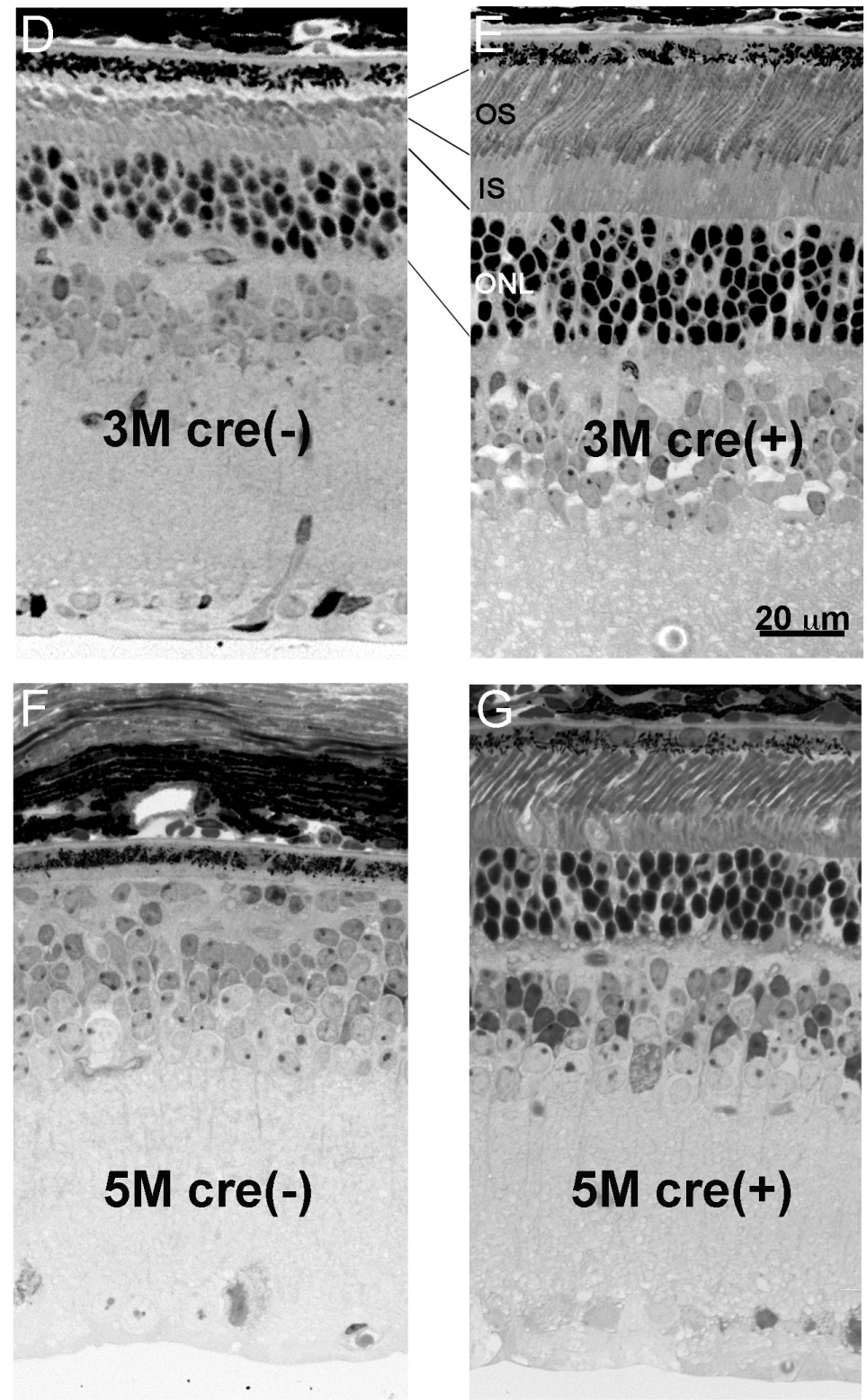
770 Figure 3. Excision of the floxed neomycin cassette restores CNG channel expression and 771 rescues rod cell death. (A) PCR primers 1, 2, and 3 were designed to detect the presence or 772 absence of the neoloxP cassette. Littermate mice were treated with tamoxifen (TM) for the 773 indicated number of days starting at 4 weeks and retinal DNA was extracted from mice at 8 774 weeks. Control retinal DNA " $c$ " is from a germline-floxed mouse wherein the neoloxP cassette 775 has been removed in all tissues (Cngb1 $\triangle$ CaM). (B) Western blots of retinal homogenates from 776 cre-negative and cre-positive littermate mice of the indicated ages (6 weeks, 8 weeks) that were 777 treated with TM or vehicle (corn oil) beginning at 4 weeks old for four consecutive days. (C)

778 Western blot of retinal homogenate prepared from the contralateral eye from mice used in $(A)$. 779 Representative retinal morphology $(\mathrm{N}=3)$ of $3 \mathrm{MO}$ cre-negative $(\mathrm{D})$ or cre-positive littermates 780 (E) mice treated with tamoxifen for 7 consecutive days beginning at 4 weeks. TM-treatment of 781 cre-positive mice showed improved outer segment (OS) length and thicker outer nuclear layer 782 (ONL), indicating a halt on cell death. (F) cre-negative and (G) cre-positive littermates treated 783 with tamoxifen for 4 consecutive days starting at P28, and retinal morphology was examined at 7845 months of age (representative image from $N \geq 3$ ). Scale bar $=20 \mu \mathrm{m}$. 

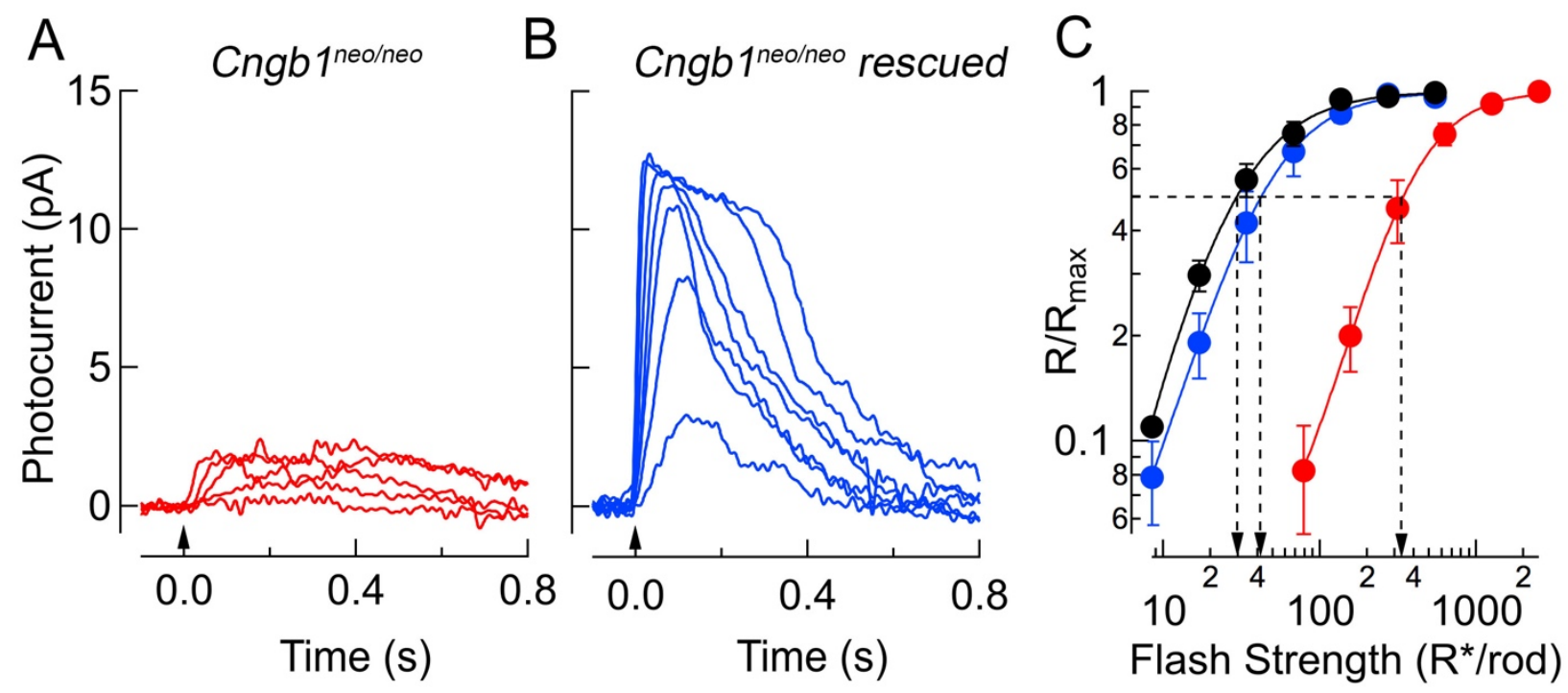

Figure 4. Light sensitivity is improved following expression of CNGB1. (A) Single cell recordings show small, desensitized response families in $C n g b 1^{\text {neo/neo }}$ mice likely reflecting residual CNG channels composed of CNGA1 monomers. Flashes generated 79, 160, 310, 270, 1300, and $2500 \mathrm{Rh} / \mathrm{rod}$. (B) Following tamoxifen treatment, rod responses showed amplitudes and sensitivity resembling those of C57; flash strengths were 9, 17, 34, 68, 140, 270, and 540 $\mathrm{Rh}^{*} /$ rod. (C) Response-intensity relationships from single-cell recordings display $\sim 10$-fold reduction in sensitivity between WT (black dots) and $C n g b 1^{\text {neo/neo }}$ (red dots) $\left(\mathrm{l}_{1 / 2}\right.$ values were $27 \pm$ $4(n=5)$ and $360 \pm 8(n=9)$, respectively). This sensitivity shift is nearly restored following reintroduction of the CNGB1 (blue dots; $l_{1 / 2}=43 \pm 3(n=10)$ ). 

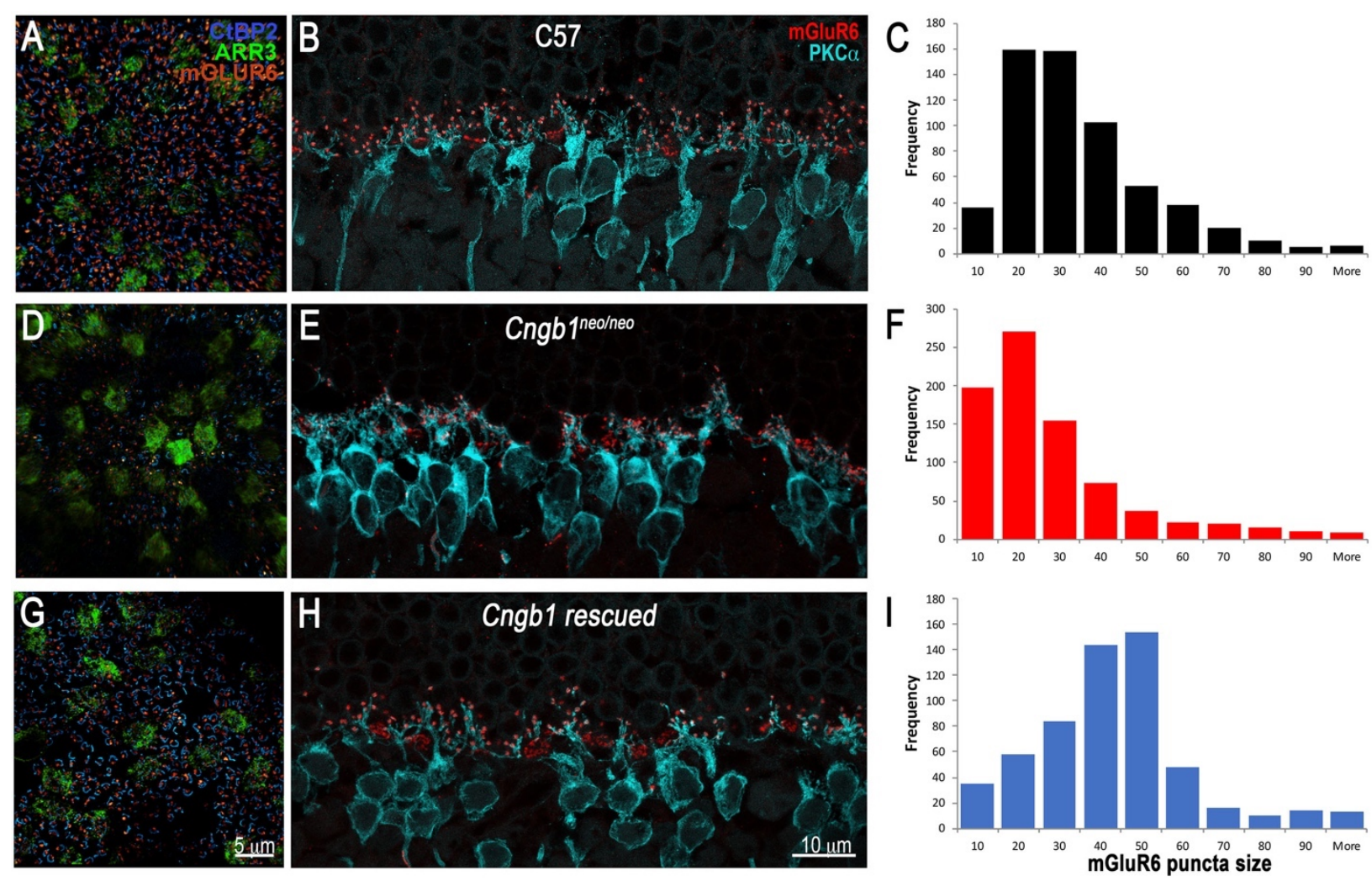

Figure 5. Expression of CNGB1 reverses pre- and postsynaptic retinal remodeling in $C n g b 1^{\text {neo/neo }}$ retina. Shown are representative images from $N>3$ independent experiments. A, D and $\mathrm{G}$ are retinal flat mounts from $1 \mathrm{MO}$ C57, $1 \mathrm{MO}$ Cngb $1^{\text {neo/neo }}$ and $3 \mathrm{MO}$ rescued Cngb1 mice treated with tamoxifen for 7 consecutive days beginning at 4 weeks of age, respectively. The flat mounts were stained with the pre-synaptic ribbon marker, CtBP2 (blue), and post-synaptic marker mGluR6 (orange). Cone pedicles were visualized using cone arrestin, ARR3 (green). B, $\mathrm{E}$ and $\mathrm{H}$ are retinal cross sections from mice of the same genotype as the flat mounts. The retinal sections were stained with antibodies to mGluR6 (red) and the rod bipolar cell marker, PKC $\alpha$ (teal). C, F and I are frequency vs. mGluR6 puncta size distributions for $1 \mathrm{MO}$ C57, $1 \mathrm{MO}$ $\mathrm{Cngb}^{\text {neo/neo }}$ and $3 \mathrm{MO}$ rescued $\mathrm{Cngb1}$ mice treated with tamoxifen. 


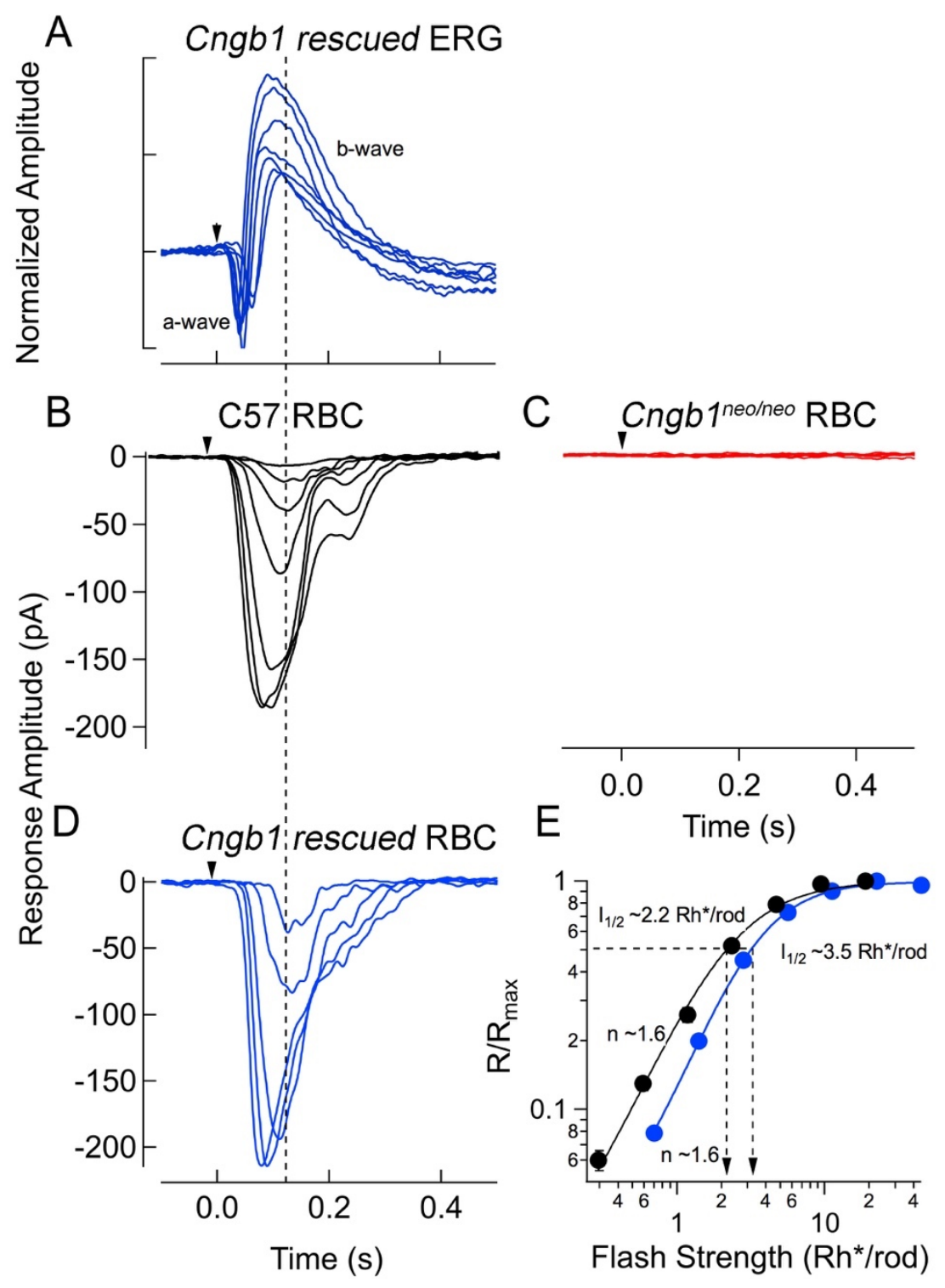

Figure 6. Physiological responses from rod bipolar cells in retinal slices. A. Ex-vivo ERG responses from 3 to $6 \mathrm{MO}$ mice after tamoxifen treatments show near normal a- and b-waves. Flashes generated 2, 9, 35, 140, 550, and $2200 \mathrm{Rh} / \mathrm{rod}$. Please compare against Fig. 2A. Voltage-clamp rod bipolar cell recordings $\left(\mathrm{V}_{\mathrm{m}}=-60 \mathrm{mV}\right)$ from the following mice: $\mathrm{B}$. C57 rod bipolar cells (2-3 MO); C. Cngb1 $1^{\text {neo/neo }}$ rod bipolar cells (1 MO); D. Cngb1 tamoxifen-treated (3 $\mathrm{MO})$. Flashes generated 2, 4, 8, 16, 31, 62 and $130 \mathrm{Rh} / \mathrm{rod}$ for $\mathrm{C} 57$ rod bipolar cells, and 280, 560, 1100 and $2200 \mathrm{Rh}$ /rod for $\mathrm{Cngb} 1^{\text {neo/neo }}$ rod bipolar cells. Light-evoked responses were never observed in Cngb $1^{\text {neo/neo }}$ rod bipolar cells (15 cells across 5 retinas - flashes generated $2200 \mathrm{Rh}^{*} / \mathrm{rod}$ ). E.Response-intensity relationships from mean data show that this relationship is shifted to higher flash strengths in rescued mice, reflecting some rod loss. The Hill exponent of rod bipolar cells were similar to normal following rod recovery (Hill exponent $=1.6 \pm 0.05$ $(n=12))$, in support of a restoration of the normal rod-to-rod bipolar cell synaptic structure and the dark rate of glutamate release. 


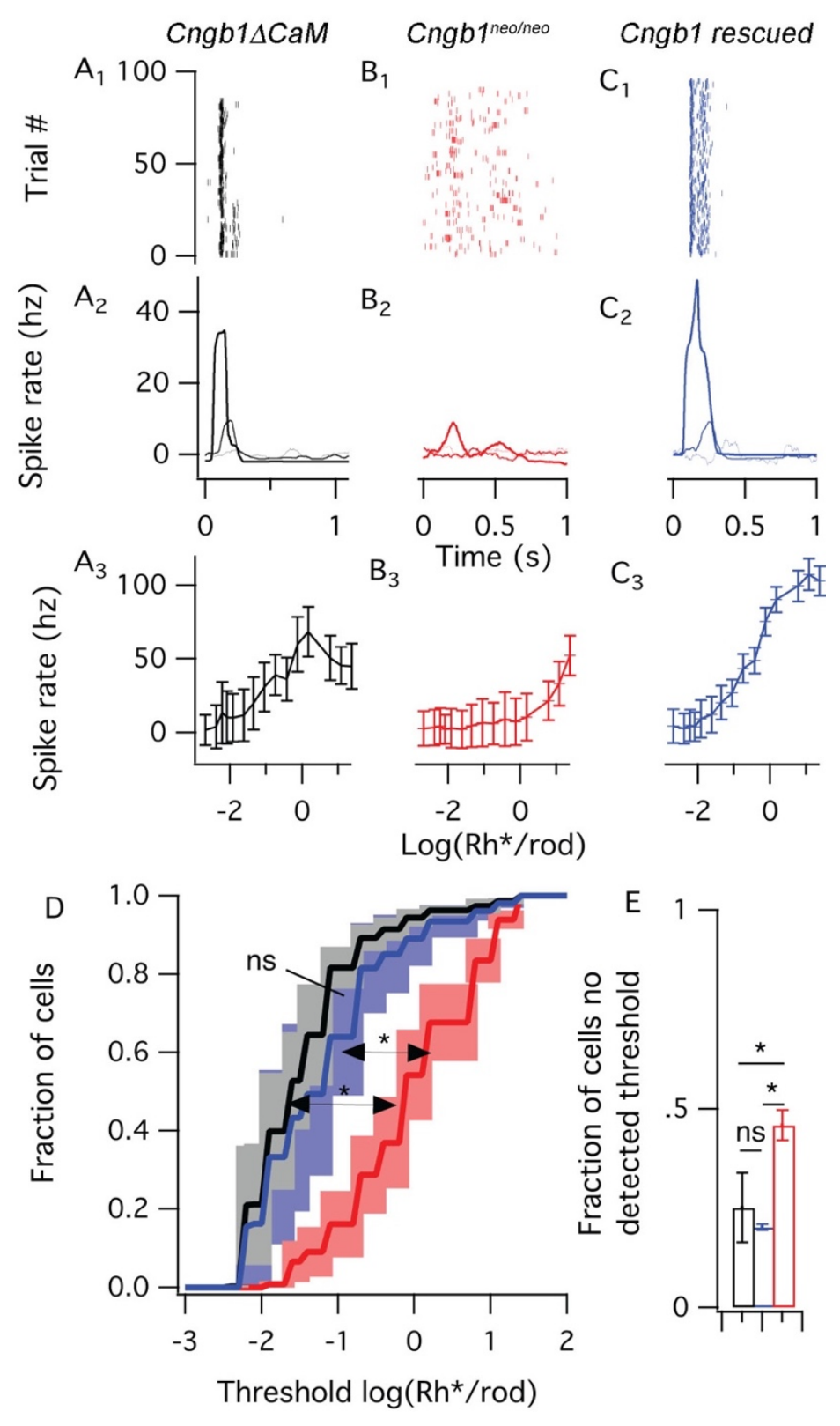

Figure 7. Dim flash responses from retinal ganglion cells (RGCs) in whole mount retina show recovery from early rod rescue. The top panels $\left(A-C_{1}\right)$ show spike times of 100 trials of 3 example cells to a single dim flash $(0.75 \mathrm{Rh} / \mathrm{rod})$. The middle panels $\left(A-C_{2}\right)$ shows PSTHs for three increasingly bright $\operatorname{dim}$ flashes $(0.002,0.02,0.75, \mathrm{Rh} / \mathrm{rod})$. The bottom panels $\left(A-C_{3}\right)$ show the mean spike rate $\pm S D$, measured on each trial in a $100 \mathrm{~ms}$ window around the peak of the PSTH. Dim flash thresholds were estimated from these curves for 1954 cells. The average cumulative distribution function show higher thresholds responses in Cngb1 ${ }^{\text {neo/neo }}$ mice RGCs than Cngb1 $\triangle$ CaM and tamoxifen-treated Cngb1 $1^{\text {neo/neo }}$ mice RGCs (D). The shaded regions illustrating SEMs across (3-5 experimental preparations). Additionally, flash thresholds could not be identified in a larger portion of RGCs from $C n g b 1^{\text {neo/neo }}$ mice $(E)$. 